\section{Birth cohort differences in the use of medications in a Brazilian population of older elderly: the Bambuí Cohort Study of Aging (1997 and 2008)}

\author{
Diferenças de coorte por nascimento no uso de \\ medicamentos em uma população brasileira \\ de idosos mais velhos: Estudo de Coorte \\ de Idosos de Bambuí (1997 e 2008)
}

Antônio Ignácio de Loyola Filho 1,2 Josélia O. A. Firmo 1 Elizabeth Uchôa 1 Maria Fernanda Lima-Costa 1

\footnotetext{
1 Núcleo de Estudos em Saúde Pública e Envelhecimento, Fundação Oswaldo Cruz/Universidade Federal de Minas Gerais, Belo Horizonte, Brasil.

2 Escola de Enfermagem, Universidade Federal de Minas Gerais, Belo Horizonte, Brasil.

Correspondence A. I. Loyola Filho Núcleo de Estudos em Saúde Pública e Envelhecimento, Fundação Oswaldo Cruz/ Universidade Federal de Minas Gerais.

Av. Augusto de Lima 1715, 6o andar, Belo Horizonte, $M G$ 30190-003, Brasil. aloy@cpqrr.fiocruz.br
}

\begin{abstract}
This study examined differences in the use of medications in two birth cohorts (born from 1916 to 1926 and from 1927 to 1937) among older elderly in the population-based cohort study in Bambuí, Minas Gerais State, Brazil. The study used data on participants who were 71-81 years of age in the baseline survey in $1997(n=492)$ and in the 11th wave, in $2008(n=620)$. The number of medications currently consumed (mean $=4.6$ and 3.4, respectively) and prevalence of polypharmacy (46.6\% and $29.1 \%$, respectively) were higher in the more recent cohort as compared to the earlier one. These differences were independent of gender, age, schooling, number of medical visits in the previous 12 months, and number of chronic conditions. The more recent cohort showed significant differences in the use of psychoactive drugs, lipid modifying agents, drugs for diabetes, and antithrombotic agents, as well as changes in drugs used for arterial hypertension. In general, these changes are consistent with those observed in elderly populations in high-income countries.
\end{abstract}

Drug Utilization; Aged; Cohort Studies

\section{Introduction}

Brazil has experienced a rapid demographic change marked by population aging. From 1970 to 2000 , the proportion of elderly (60 years or older) increased from $5.1 \%$ to $8.6 \% 1$, reaching 10\% by 2009 (Departamento de Informática do SUS. Informações Demográficas. http://tabnet. datasus.gov.br/cgi/tabcgi.exe?ibge/cnv/popuf. def, accessed on 27/Oct/2010). With population aging, chronic health conditions gain greater visibility in the healthcare scenario, due to the increase in their prevalence and the presence of comorbidities 2 .

The high prevalence of chronic illnesses among the elderly is associated with high consumption of medications by this population group ${ }^{3}$. In the elderly population, the risks associated with consumption of medications compete with the expected benefits, due to the physiological changes proper to aging, including the decrease in muscle mass and body water, with effects on the pharmacodynamics and pharmacokinetics of medications. Thus, unwanted effects (adverse effects and drug-drug interactions) are more likely to occur 4.

The prevalence of polypharmacy is high in the elderly 5,6,7, and is one of the strongest predictors of health problems associated with use of medications 4 . Polypharmacy is defined as the use of multiple medications, a basically quantita- 
tive concept, which does not take the pertinence of their utilization into account 8 . The characteristics most consistently associated with polypharmacy are female gender, more advanced age, chronic illness, and greater utilization of health services 6,7,9. Increasing polypharmacy has been observed in elderly populations in high-income countries 10,11 .

Studies in other countries 12,13,14 and in Brazil 15,16 have identified drugs for the cardiovascular system, central nervous system, metabolism, and alimentary tract as the most frequently consumed among the elderly. More recently, changes in the pattern of use of some drug classes have been observed in some populations, especially in the pattern of consumption of drugs for hypertension 17,18 , as well as an increase in the use of lipid modifying 5,17, psychoactive 19,20, and antiepileptic drugs 21.

In Brazil, pharmacoepidemiological studies have described the prevalence of polypharmacy and associated factors and the most widely consumed drug classes among the elderly population 7,15,16. However, to our knowledge, no study has been done on differences over time in drug use patterns in this population.

The current study used data from the baseline (1997) and the $11^{\text {th }}$ wave (2008) from the Bambuí Cohort Study of Aging in order to investigate birth cohort differences in polypharmacy and the amounts and classes of drugs used.

\section{Methodology}

\section{Study area and population}

The Bambuí Cohort Study of Aging has been conducted in the city of the same name (with some 15,000 inhabitants), located in the State of Minas Gerais, in Southeast Brazil. The population for the baseline cohort was identified through a complete census of the city conducted in November-December 1996. Among the 1,742 residents 60 years or older on January 1, 1997, 1,606 participated in the baseline cohort. Since then, members of cohort have been followed up annually. From 1997 to 2008 (the 11th wave), 641 participants died, and only $6 \%$ were lost to follow-up. Further details have been published elsewhere 22,23.

All the participants in the baseline survey and $11^{\text {th }}$ wave and with ages between 71 and 81 years, corresponding to the births in 1916-1926 and 1927-1937, respectively, were selected for the present study.

\section{Data collection and study variables}

Information on consumption of medications was obtained through home interviews, with verification of the product package and/or medical prescription. All the medications were identified, broken down according to their active ingredients, and classified according to the Anatomical Therapeutic Chemical (ATC) Index (World Health Organization Collaborating Centre for Drug Statistics Methodology. ATC/DDD Index 2011. http://www.whocc.no/atc_ddd_in dex/, accessed on Sep/2010). The current study used the classifications corresponding to levels 1 (anatomical) and 2 (therapeutic), considering over-the-counter and prescription drugs. The number of drugs consumed (counting variable) was truncated for the highest values (10 or more). Polypharmacy was defined as the use of five or more drugs 7,24 .

The other study variables were gender, age, schooling ( 0 -3 and $\geq 4$ complete years), history of medical diagnosis for chronic illnesses (arterial hypertension, coronary disease - myocardial infarction and/or angina -, Chagas disease, diabetes, and arthritis/rheumatism), and number of medical consultations in the previous 12 months. The number of chronic conditions and number of medical consultations were dichotomized (exposure was defined as values greater than the median).

The data collection instruments and procedures were the same in the 1997 and 2008 surveys. The interviews were conducted by members of the community with more than 11 years of schooling and who were certified after training by the research team.

\section{Data analysis}

Data analysis was based on the Pearson chisquare test (for comparison of frequencies) and the Student $t$ test (for comparison of means). Univariate and multivariate Poisson regression models with robust variance were used to estimate prevalence ratios and respective $95 \%$ confidence intervals $(95 \% \mathrm{CI})$ to examine the factors associated with use of medications. Gender, age, schooling, number of chronic conditions or illnesses, and number of medical consultations in the previous 12 months were considered $a$ priori confounding variables in these analysis, since they had been described previously as factors associated with the use of medications in the underlying population base for the Bambuí cohort 6,25. All the analyses used Stata, version 10 (Stata Corp., College Station, USA), with significance set at $\mathrm{p}<0.05$. 
The Bambuí Cohort Study of Aging was approved by the Ethics Research Committee of the Oswaldo Cruz Foundation (Fundação Oswaldo Cruz), Rio de Janeiro, Brazil 22,23.

\section{Results}

All 492 participants in the 1997 survey ranging from 71 to 81 years of age had information on the use of medications and were included in the present analysis. Of the 657 cohort survivors in 2008 and in the same age bracket, 620 (94.4\%) had the corresponding information and were included in this study. Participants and non-participants were similar in relation to gender $(p=0.106)$, age $(\mathrm{p}=0.511)$, and schooling $(\mathrm{p}=0.254)$.

Table 1 shows some characteristics of the study participants in 1997 and 2008. No differences were observed between the two groups in terms of gender $(60 \%$ and $64.5 \%$ were women, respectively) or mean age (75.1 years in both years). From 1997 to 2008, there were significant increases in schooling $(29.7 \%$ and $39.2 \%$ had $\geq 4$ years of schooling, respectively), prevalence of two or more chronic illnesses $(41.2 \%$ and $54.1 \%$, respectively), and number of medical visits in the previous 12 months (30.5\% and $42 \%$ had four or more medical visits, respectively).
Prevalence of the use of at least onemedication (88.8\% and $93.6 \%$, respectively), mean number of medications used (3.4 and 4.6, respectively), and prevalence of polypharmacy $(29.1 \%$ and $46.6 \%$, respectively) were higher in the more recent cohort as compared to the earlier one, as shown in Table 2. The association between birth cohort and number of medications consumed (PR = 1.19; 95\%CI: 1.11-1.28) and prevalence of polypharmacy ( $\mathrm{PR}=1.35$; 95\%CI: 1.15-1.57) remained even after adjusting for age, gender, schooling, number of medical visits, and number of chronic illnesses. The association between birth cohort and use of at least one medication lost statistical significance after adjusting for these same variables (PR = 1.03; 95\%CI: 0.99-1.06).

Table 3 shows the number of medications consumed in each cohort, stratified by gender and age bracket. Significant increases were observed in the mean number of medications used in the more recent cohort as compared to the earlier one, both among men (from 2.6 to 3.6) and women (from 3.9 to 5.1). These increases were observed consistently in the 71-75-year age bracket (from 2.0 to 2.7 in men and from 2.8 to 4.1 in women) and the 76-81-year bracket (from 2.5 to 2.9 in men and from 4.0 to 5.2 in women). Overall, the mean number of medications consumed was consistently higher among women in both cohorts.

Selected characteristics of study participants. The Bambuí Cohort Study of Aging, 1997 and 2008.

\begin{tabular}{|c|c|c|c|}
\hline \multirow[t]{2}{*}{ Characteristics } & $1997(n=492)$ & $2008(n=620)$ & \multirow[t]{2}{*}{$\mathrm{p}$-value * } \\
\hline & $\%$ or mean (SD) & $\%$ or mean (SD) & \\
\hline \multicolumn{4}{|l|}{ Gender } \\
\hline Male & 40.0 & 35.5 & \\
\hline Female & 60.0 & 64.5 & 0.119 \\
\hline Age & $75.1(3.2)$ & $75.1(3.0)$ & 0.995 \\
\hline \multicolumn{4}{|c|}{ Schooling (in complete years) } \\
\hline $0-3$ & 70.3 & 60.8 & \\
\hline$\geq 4$ & 29.7 & 39.2 & 0.001 \\
\hline \multicolumn{4}{|c|}{ Number of chronic conditions ** } \\
\hline $0-1$ & 58.9 & 45.9 & \\
\hline$\geq 2$ & 41.2 & 54.1 & $<0.001$ \\
\hline \multicolumn{4}{|c|}{ Number of medical consultations in the previous 12 months } \\
\hline $0-3$ & 69.5 & 58.0 & \\
\hline$\geq 4$ & 30.5 & 42.0 & $<0.001$ \\
\hline
\end{tabular}

SD: standard deviation.

* $p$-value: Pearson chi-square test for differences between frequencies and Student $t$ test for differences between means;

** History of medical diagnosis of hypertension, coronary disease (angina and/or myocardial infarction), diabetes, Chagas

disease and arthritis/rheumatism. 
Use of medications by older elderly in the earlier cohort (born 1916-1926) and more recent cohort (born 1927-1937). The Bambuí Cohort Study of Aging, 1997 and 2008.

\begin{tabular}{|c|c|c|c|c|c|c|}
\hline Use of medications & $\begin{array}{c}\text { Earlier cohort } \\
\qquad(\mathrm{n}=491)\end{array}$ & $\begin{array}{l}\text { Recent cohort } \\
\quad(n=620)\end{array}$ & $\begin{array}{c}\text { Adjusted PR * } \\
(95 \% \mathrm{Cl})\end{array}$ & $\begin{array}{c}\text { Adjusted PR ** } \\
(95 \% \mathrm{Cl})\end{array}$ & $\begin{array}{c}\text { Adjusted PR *** } \\
(95 \% \mathrm{Cl})\end{array}$ & $\begin{array}{c}\text { Adjusted PR \# } \\
(95 \% \mathrm{Cl})\end{array}$ \\
\hline Use of at least 1 medication (\%) & 88.8 & 93.6 & 1.05 (1.01-1.09) & 1.05 (1.01-1.09) & $1.04(1.00-1.08)$ & $1.03(0.99-1.06)$ \\
\hline Number of medications [mean (SD)] & $3.4(2.5)$ & $4.6(3.0)$ & $1.31(1.21-1.41)$ & $1.31(1.21-1.41)$ & $1.24(1.15-1.34)$ & $1.19(1.11-1.28)$ \\
\hline Polypharmacy \#\# (\%) & 29.1 & 46.6 & $1.56(1.33-1.83)$ & $1.58(1.35-1.85)$ & $1.46(1.25-1.71)$ & $1.35(1.15-1.57)$ \\
\hline
\end{tabular}

PR ( $95 \% \mathrm{Cl})$ : prevalence ratio (95\% confidence interval) estimated by multivariate Poisson regression with robust variance.

* Adjusted by gender and age;

** Adjusted by gender, age, and schooling;

*** Adjusted by gender, age, schooling, and number of medical consultations;

\# Adjusted by gender, age, schooling, number of medical consultations, and number of chronic conditions/illnesses;

\#\# Use of five or more medications.

Table 3

Mean number of medications consumed by older elderly in the earlier cohort (born 1916-1926) and more recent cohort (born 1927-1937). The Bambui Cohort Study of Aging, 1997 and 2008.

\begin{tabular}{lccc}
\hline Gender/Age bracket (years) & $\begin{array}{c}\text { Earlier cohort } \\
\text { Mean (DP) }\end{array}$ & $\begin{array}{c}\text { More recent cohort } \\
\text { Mean (DP) }\end{array}$ & p-value * \\
\hline Men & & & 0.003 \\
$71-75$ & $2.4(2.0)$ & $3.3(2.7)$ & 0.003 \\
$76-81$ & $2.8(2.6)$ & $4.1(3.2)$ & $<0.001$ \\
Women & & & $<0.001$ \\
$71-75$ & $3.9(2.5)$ & $5.0(2.9)$ & $<.2(3.1)$ \\
$76-81$ & $4.0(2.3)$ & $3.6(2.9)$ & $<0.001$ \\
All men & $2.6(2.3)$ & $5.1(3.0)$ & $<0.001$ \\
All women & $3.9(2.5)$ & $<0.001$ & \\
P-value * & $<0.001$ & & \\
\hline
\end{tabular}

SD: standard deviation.

* Student t test.

As shown in Figure 1, the most frequently consumed medications in both cohorts were those acting on the cardiovascular system $(57.7 \%$ and $80.7 \%$, respectively), followed by the nervous system (52.6\% and $63.4 \%)$, and alimentary tract and metabolism (43.9\% and $44.5 \%)$. The use of medications acting on the cardiovascular system (code $\mathrm{C}$ ), nervous system (code $\mathrm{N}$ ), and blood and blood forming organs (code B) was significantly higher in the more recent as compared to the earlier cohort. No statistically significant differences were observed between the two cohorts in the use of medications for the alimentary tract and metabolism (code A) or for drugs acting on the musculoskeletal system (code M).
As shown in Table 4, the five classes of medications (level 2 therapeutic classification) most widely used by the elderly in the older cohort were, in decreasing order: diuretics $(29.1 \%)$, vitamins (25.6\%), cardiac therapy $(24.8 \%)$, psycholeptics $(22.4 \%)$, and analgesics (19.5\%). Among individuals from the more recent cohort, the highest prevalence rates were for consumption of agents acting on the renin-angiotensin system (48.2\%), diuretics $(41.6 \%)$, beta blocking agents (35.3\%), antithrombotic agents (33.1\%), and analgesics (26.3\%).

Differences between the two cohorts (Table 4) also included significant increases in various medications acting on the cardiovascular 
Use of medications by older elderly in the earlier cohort (born 1916-1926) and more recent cohort (born 1927-1937), according to level 1 of the Anatomical Therapeutic Chemical (ATC) Index *. The Bambui Cohort Study of Aging, 1997 and 2008.

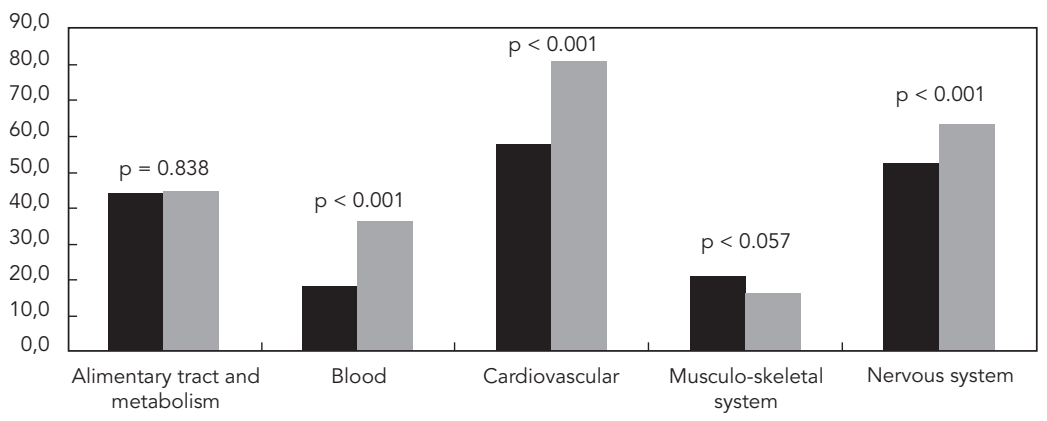

Earlier cohort

More recent cohort metabolism

* World Health Organization Collaborating Centre for Drug Statistics Methodology (ATC/DDD Index 2011.

http://www.whocc.no/atc_ddd_index/, accessed on Sep/2010).

Table 4

Use of medications by older elderly in the earlier cohort (born 1916-1926) and more recent cohort (born 1927-1937), according to level 2 of the Anatomical Therapeutic Chemical (ATC) Index *. The Bambuí Cohort Study of Aging, 1997 and 2008.

\begin{tabular}{|c|c|c|c|}
\hline Medications (codes) & $\begin{array}{c}\text { Earlier cohort } \\
\%\end{array}$ & $\begin{array}{c}\text { More recent cohort } \\
\%\end{array}$ & $\operatorname{PR}(95 \% \mathrm{Cl})$ \\
\hline \multicolumn{4}{|l|}{ Cardiovascular system (C) } \\
\hline Cardiac therapy (C01) & 24.8 & 19.2 & $0.76(0.61-0.95)$ \\
\hline Antihypertensives (C02) & 8.5 & 6.6 & $0.76(0.50-1.14)$ \\
\hline Diuretics (C03) & 29.1 & 41.6 & $1.41(1.20-1.67)$ \\
\hline Beta blocking agents (CO7) & 6.1 & 35.3 & $5.71(3.97-8.20)$ \\
\hline Calcium channel blockers (C08) & 13.2 & 18.9 & $1.40(1.06-1.84)$ \\
\hline Agents acting on the renin-angiotensin system (C09) & 10.4 & 48.2 & $4.61(3.51-6.06)$ \\
\hline Lipid modifying agents (C10) & 0.8 & 13.7 & $16.48(6.09-44.57)$ \\
\hline \multicolumn{4}{|l|}{ Nervous system (N) } \\
\hline Analgesics (N02) & 19.5 & 26.3 & $1.33(1.06-1.65)$ \\
\hline Antiepileptics (N03) & 6.9 & 21.6 & $3.10(2.17-4.42)$ \\
\hline Psycholeptics (N05) & 22.4 & 20.2 & $0.88(0.70-1.10)$ \\
\hline Psychoanaleptics (N06) & 9.6 & 22.4 & $2.28(1.68-3.10)$ \\
\hline \multicolumn{4}{|l|}{ Alimentary tract and metabolism (A) } \\
\hline Drugs used in diabetes (A10) & 6.9 & 18.4 & $2.64(1.83-3.80)$ \\
\hline Vitamins (A11) & 25.6 & 12.3 & $0.47(0.36-0.61)$ \\
\hline \multicolumn{4}{|l|}{ Musculo-skeletal system (M) } \\
\hline Antiinflammatory and antirheumatic products (M01) & 15.5 & 12.1 & $0.76(0.57-1.02)$ \\
\hline \multicolumn{4}{|l|}{ Blood and blood forming organs (B) } \\
\hline Antithrombotic agents (B01) & 17.5 & 33.1 & $1.88(1.51-2.35)$ \\
\hline
\end{tabular}

PR (95\% Cl): prevalence ratio (95\% confidence interval) estimated according to univariate Poisson regression with robust variance. * World Health Organization Collaborating Centre for Drug Statistics Methodology (ATC/DDD Index 2011. http://www.whocc. no/atc_ddd_index/, accessed on Sep/2010). 
system: lipid modifying agents $(\mathrm{PR}=16.48$; 95\%CI: 6.09-44.57); beta blocking agents (PR $=5.71$; 95\%CI: 3.97-8.20); agents acting on the renin-angiotensin system $(\mathrm{PR}=4.61 ; 95 \% \mathrm{CI}$ : 3.51-6.06); diuretics ( $\mathrm{PR}=1.41 ; 95 \% \mathrm{CI}: 1.20$ 1.67), and calcium channel blockers ( $\mathrm{PR}=1.40$; 95\%CI: 1.06-1.84); meanwhile, the use of cardiac therapy decreased significantly $(\mathrm{PR}=0.76$; 95\%CI: 0.61-0.95). As for medications acting on the nervous system, there was an increase in the use of antiepileptics, psychoanaleptics, and analgesics, especially in the first two $(\mathrm{PR}=3.10$; 95\%CI: 2.17-4.42 and PR = 2.28; 95\%CI: 1.68-3.10, respectively). Medications acting on the alimentary tract and metabolism showed an increase in drugs used in diabetes $(\mathrm{PR}=2.64 ; 95 \% \mathrm{CI}$ : 1.83-3.80) and a decrease in the use of vitamins $(\mathrm{PR}=0.47 ; 95 \% \mathrm{CI}: 0.36-0.61)$. Finally, the more recent cohort showed an increase over the earlier cohort in the use of antithrombotic agents $(\mathrm{PR}=1.88$; 95\%CI: 1.51-2.25).

\section{Discussion}

The current study's findings showed an important increase in the number of medications consumed and in the prevalence of polypharmacy in the more recent cohort as compared to the earlier cohort. The association between birth cohort and use of medications was not affected by age, gender, or schooling. Adjustments according to number of medical visits and number of chronic illnesses attenuated these associations, but they still remained statistically significant.

The results are consistent with findings in elderly populations in high-income countries. Studies in Finland and the United States have shown an increase in both the number of medications consumed by the elderly and polypharmacy 10,11 . The explanations for this increase relate to socio-cultural and political issues linked to healthcare and technological advances in this area. This includes issues with a greater supply and expanded access to health services, greater participation by medications in healthcare, expansion of the therapeutic armamentarium, changes in treatment approaches, and prescription habits 10,12, in addition to growing availability of over-the-counter drugs 26 .

In the current study, women in both cohorts used more medications than men. These findings are consistent with previous observations in studies both in Brazil 16 and elsewhere 9,13,14. Greater use of medications by women can be explained, at least in part, by greater use of healthcare services, greater knowledge of medications, quantitative and qualitative differences in dis- ease patterns, and greater attention to their own health problems 16 .

In the current study, the most widely used drug classes (cardiovascular, nervous system, alimentary tract and metabolism, blood and blood forming organs, and musculoskeletal system) reproduce a consumption pattern observed in elderly populations in different countries 13,14 and in Brazil 15,16. The use of these drug classes relates to treatment and prevention of typical health events for this phase of life, like hypertension, coronary disease, diabetes, and chronic pain.

Considering the therapeutic classification, the study showed important differences between the two cohorts in the medications used for management of hypertension and more specifically, an increase in the use of beta blocking agents, agents acting on the renin-angiotensin system, diuretics, and calcium channel blockers. The increase in the use of medications is consistent with findings from other studies 17,18 and the prevailing guidelines for treatment of hypertension 27, as well as Brazilian Ministry of Health (Ministério da Saúde) protocols for reorganization of treatment of hypertension 28 . Importantly, there was an important increase in the use of lipid modifying agents, a trend also present in other populations 5,17 , as well as in the use of antithrombotic agents. Both medications are used to decrease cardiovascular risk 17,29.

Among agents acting on the nervous system, there were important increases in the use of antiepileptics and psychoanaleptics in the more recent cohort. Recent increases have been observed in the use of antiepileptics in other elderly populations 21,30. The prevalence of epilepsy among the elderly is relatively low, varying from $1 \%$ to $3 \%$ 31,32 . Thus, it is unlikely that increases in the incidence and/or prevalence of this condition would explain the increase from $7 \%$ to $22 \%$ in the use of antiepileptics in the current study. It is more likely that these medications are being used for other therapeutic purposes, such as pain relief, prevention of migraine, management of bipolar disorder, or neurological treatment of patients with a history of stroke 21,30 . In addition, studies in high-income countries 19,20 have shown an increase in the use of psychoactive drugs, both psychoanaleptics and psycholeptics 33 . The current study showed an increase in the use of the former, but not the latter.

As for medications for the alimentary tract and metabolism, there was an increase of 2.6 times in the prevalence of drugs used in diabetes, which is consistent with the increase in the prevalence of diabetes mellitus among the older elderly in the Bambuí cohort ${ }^{34}$. Meanwhile, there 
was a decrease in the use of vitamins in the more recent cohort as compared to the earlier. Vitamins are viewed as maintaining overall health 3 and as a source of essential nutrients, and their consumption has decreased in recent years as a result of changes in eating habits 3,35 . They are commonly used in the absence of health problems and without a medical prescription 36 and concurrently with other prescribed medications, which increases the risk of drug-drug interactions 5. Thus, and given the lack of evidence of the benefits of using such medications to prevent chronic illnesses 37 , the decrease in prevalence of their use, as observed here, can be considered a positive trend.

This study has advantages and limitations. The advantages include its population-based design and the uniformity of its data collection procedures, making the data comparable, in addition to the small losses to follow-up, which reduced the probability of a non-participation bias. The response rate was high in both 1997 and 2008. In the first year, all the participants had information on the use of medications. In 2008, the corresponding response rate was somewhat

\section{Resumo}

Foram examinadas diferenças de coorte (entre nascidos em 1916-1926 e em 1927-1937) no uso de medicamentos entre idosos participantes do Estudo de Coorte de Idosos de Bambuí. Foram utilizados dados dos participantes com 71-81 anos de idade da linha de base em 1997 ( $n=492)$ e do 11 o ano de seguimento em 2008 $(n=620)$. O número de medicamentos consumidos (média $=4,6$ e 3,4, respectivamente) e a prevalência da polifarmácia (46,6\% e 29,1\%, respectivamente) foram mais altos na coorte recente, em comparação à antiga. Essas diferenças foram independentes do sexo, idade, escolaridade, número de consultas médicas e número de doenças crônicas. Na coorte mais jovem, observaram-se aumentos significativos no uso de psicofármacos, agentes modificadores de lipídios, hipoglicemiantes e antitrombóticos, assim como mudanças nos medicamentos utilizados para o controle da hipertensão arterial. De maneira geral, essas mudanças são consistentes com o observado em populações idosas de países de alta renda.

Uso de Medicamentos; Idoso; Estudos de Coortes lower (94.5\%). However, this appears not to have affected the results, since participants and nonparticipants were similar in terms of age, gender, and schooling. Finally, this study was done in a population of older elderly living in the city of Bambuí, and it may not be possible to generalize the results to other populations. Still, it is important to highlight that the most important findings were consistent with those in elderly populations in other countries.

In short, the current study's findings show important changes in the pattern of medication use in the more recent birth cohort as compared to the earlier one. The main differences were increases in the number of medications consumed, polypharmacy, psychoactive drugs, lipid modifying drugs, drugs used in diabetes, and antithrombotic agents, as well as changes in the drugs used to control hypertension. In general, these changes are consistent with findings in elderly populations in high-income countries. Further studies are recommended to examine the benefits or disadvantages of these changes for health conditions in the elderly.

\section{Contributors}

A. I. Loyola Filho conceived the project, was responsible for the data analysis and interpretation, drafted the article, and approved the final version. J. O. A. Firmo participated in the data collection, interpretation of the results, and critical analysis of the article. E. Uchôa and M. F. Lima-Costa collaborated in the project's conceptualization, data collection, critical revision of the article, and approval of the final version.

\section{Acknowledgments}

The authors wish to thank FINEP, FAPEMIG and CNPq for their financial support. 


\section{References}

1. Carvalho JAM, Garcia RA. O envelhecimento da população brasileira: um enfoque demográfico. Cad Saúde Pública 2003; 19:725-33.

2. Wolff JL, Starfield B, Anderson G. Prevalence, expenditures, and complications of multiple chronic conditions in the elderly. Arch Intern Med 2002; 162:2269-76.

3. Kaufman DW, Kelly JP, Rosenberg L, Anderson TE, Mitchell AA. Recent patterns of medication use in the ambulatory adult population of the United States. JAMA 2002; 287:337-44.

4. Tamblyn R. Medication use in seniors: challenges and solutions. Therapie 1996; 51:269-82.

5. Qato DM, Alexander GC, Conti BM, Johnson M, Schumm P, Lindau ST. Use of prescription and over-the-counter medications and dietary supplements among older adults in the United States. JAMA 2010; 300:2867-78.

6. Loyola Filho AI, Uchôa E, Firmo JOA, Lima-Costa MF. Influência da renda na associação entre disfunção cognitiva e polifarmácia: Projeto Bambuí. Rev Saúde Pública 2008; 42:89-99.

7. Rozenfeld S, Fonseca MJM, Acúrcio FA. Drug utilization and polypharmacy among the elderly: a survey in Rio de Janeiro city, Brazil. Rev Panam Salud Pública 2008; 23:34-43.

8. Rollason V, Vogt N. Reduction of polypharmacy in the elderly: a systematic review of the role of the pharmacist. Drugs Aging 2003; 11:817-32.

9. Veehof L, Stewart R, Haaijer-Ruskamp F, Jong BM. The development of polyparmacy. A longitudinal study. Fam Pract 2000; 17:261-7.

10. Jylhä M. Ten-year change in the use of medical drugs among the elderly: a longitudinal study and cohort comparison. J Clin Epidemiol 1994; 47: 69-79.

11. Stewart RB, Moore MT, May FE, Marks RG, Hale WE. Changing patterns of therapeutic agents in the elderly: a ten-year overview. Age Ageing 1991; 20:182-8.

12. Linjakumpu T, Hartikainen S, Klaukka T, Veijola J, Kivelä SL, Isoaho R. Use of medications and polypharmacy are increasing among the elderly. J Clin Epidemiol 2002; 55:809-17.

13. Chen YF, Dewey ME, Avery AJ; Analysis Group of The MRCCFA Study; The Medical Research Council Cognitive Function and Ageing Study (MRC CFAS). Sel-reported medication use for older people in England and Wales. J Clin Pharm Ther $2001 ; 26: 129-40$.

14. Stewart RB, Moore MT, May FE, Marks RG, Hale WE. A longitudinal evaluation of drug use in an ambulatory elderly population. J Clin Epidemiol 1991; 44:1353-9.

15. Ribeiro AQ, Rozenfeld S, Klein CH, Cezar CC, Acúrcio FA. Inquérito sobre uso de medicamentos por idosos aposentados. Rev Saúde Pública 2008; 42:724-32.

16. Loyola Filho AI, Uchôa E, Lima-Costa MF. Estudo epidemiológico de base populacional sobre uso de medicamentos entre idosos na Região Metropolitana de Belo Horizonte, Minas Gerais, Brasil. Cad Saúde Pública 2006; 22:2657-67.
17. Ahola TL, Kantola IM, Puukka P, Kattainen A, Klaukka T, Reunanen A, et al. Positive change in the utilization of antihypertensive and lipid modifying drugs among adult CHD patients in Finland: results from a large national database between 2000 and 2006. Eur J Cardiovasc Prev Rehabil 2010; 17:477-85.

18. Wolf HK, Andreou P, Bata IR, Comeau DG, Gregor RD, Kephart G, et al. Trends in the prevalence and treatment of hypertension in Halifax County from 1985 to 1995. CMAJ 1999; 161:699-704.

19. Carrasco-Garrido P, Jiménez-García R, AstasioArbiza P, Ortega-Molina P, de Miguel G. Psychotropics use in the Spanish elderly: predictors and evolution between years 1993 and 2003. Pharmacoepidemiol Drug Saf 2007; 16:449-57.

20. Zuvekas SH. Prescription drugs and the changing patterns of treatment for mental disorders, 19962001. Health Aff 2005; 24:195-205.

21. Hollingworth SA, Eadie MJ. Antiepileptic drugs in Australia: 2002-2007. Pharmacoepidemiol Drug Saf 2010; 19:82-9.

22. Lima-Costa MF, Firmo JOA, Uchoa E. Cohort profile: The Bambuí (Brazil) Cohort Study of Ageing. Int J Epidemiol 2010; [Epub ahead of print].

23. Lima-Costa MF, Firmo JOA, Uchôa E. The Bambuí Cohort Study of Aging: methodology and health profile of participants at baseline. Cad Saúde Pública 2011; 27 Suppl 3:S327-35.

24. Klarin I, Fastbom J, Wimo A. A population-based study of drug use in the very old living in a rural district of Sweden, with focus on cardiovascular drug comsuption: comparison with an urban cohort. Pharmacoepidemiol Drug Saf 2003; 12:669-78.

25. Loyola Filho AI, Uchôa E, Firmo JOA, Lima-Costa MF. Estudo de base populacional sobre o consumo de medicamentos entre idosos: Projeto Bambuí. Cad Saúde Pública 2005; 21:545-53.

26. Lynd LD, Taylor J, Dobson R, Willison DJ. Prescription to over-the-counter deregulation: are we ready for it, or do we need to be? CMAJ 2005; 173:775-7.

27. Chobanian AV, Bakris GL, Black HR, Cushman WC, Green LA, Izzo Jr. JL, et al. The Seventh Report of the Joint National Committee on Prevention, Detection, Evaluation, and Treatment of High Blood Pressure: the JNC 7 Report. JAMA 2003; 289:2560-72.

28. Ministério da Saúde. Plano de Reorganização da Atenção da Hipertensão Arterial e Diabetes Mellitus: manual da hipertensão arterial e do diabetes mellitus. http://bvsms.saude.gov.br/bvs/publica coes/miolo2002.pdf (accessed on 27/Oct/2010).

29. Goldstein LB, Adams R, Alberts MJ, Appel LJ, Brass LM, Bushnell CD, et al. Primary prevention of ischemic stroke: a guideline from the American Heart Association/American Stroke Association Stroke Council: cosponsored by the Atherosclerotic Peripheral Vascular Disease Interdisciplinary Working Group; Cardiovascular Nursing Council; Clinical Cardiology Council; Nutrition, Physical Activity, and Metabolism Council; and the Quality of Care and Outcomes Research Interdisciplinary Working Group. Circulation 2006; 113:e873-923. 
30. Savica R, Beghi E, Mazzaglia G, Innocenti F, Brignoli $\mathrm{O}$, Cricelli $\mathrm{C}$, et al. Prescribing patterns of antiepileptic drugs in Italy: a nationwide populationbased study in the years 2000-2005. Eur J Neurol 2007; 14:1317-21

31. Cloyd J, Hauser W, Towne A, Ramsay R, Mattson R, Gilliam F, et al. Epidemiological and medical aspects of epilepsy in the elderly. Epilepsy Res 2006; 68 Suppl 1:S39-48.

32. Borges MA, Min LL, Guerreiro CAM, Yacubian EMT, Cordeiro JA, Tognola WA, et al. Urban prevalence of epilepsy: populational study in São José do Rio Preto, a medium-sized city in Brazil. Arq Neuropsiquiatr 2004; 62:199-205.

33. Linjakumpu T, Hartikainen S, Klaukka T, Koponen $\mathrm{H}$, Kivelä SL, Isoaho R. Psychotropics among the home-dwelling elderly: increasing trends. Int J Geriatr Psychiatry 2002; 17:874-83.

34. Freitas MPD, Loyola Filho AI, Lima-Costa AI. Dyslipidemia and the risk of incident hypertension in a population of community-dwelling Brazilian elderly: the Bambuí Cohort Study of Aging. Cad Saúde Pública 2011; 27 Suppl 3:S351-9.
35. Balluz LS, Kieszak MA, Philen RM, Mulinare J. Vitamin and mineral supplement use in the United States. Arch Fam Med 2000; 9:258-62.

36. Hanlon JT, Fillenbaum GG, Ruby CM, Gray S, Bohannon A. Epidemiology of over-the-counter drug use in community dwelling elderly: United States perspective. Drugs Aging 2001; 18:123-31.

37. Huang HY, Caballero B, Chang S, Alberg AJ, Semba $\mathrm{RD}$, Schneyer CR, et al. The efficacy and safety of multivitamin and mineral supplement use to prevent cancer and chronic disease in adults: a systematic review for a National Institutes of Health State-of-the-Science Conference. Ann Intern Med 2006; 145:372-85.

Submitted on $30 /$ Nov/2010

Final version resubmitted on $04 / \mathrm{Jan} / 2011$

Approved on 06/Jan/2011 